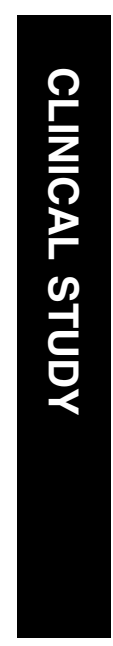

\title{
Intravitreal bevacizumab (Avastin) for age-related macular degeneration: a critical analysis of literature
}

${ }^{1}$ Department of Ophthalmology, King's College Hospital, London, UK

\section{${ }^{2}$ Department of} Ophthalmology, Sohag University Hospital, Sohag, Egypt

Correspondence:

S Sivaprasad,

Laser and Retinal Research Unit,

King's College Hospital,

Denmark Hill,

London SE5 9RS, UK

Tel: 02032994548 ;

Fax: 02032993738

E-mail: senswathi@

aol.com

Received: 28 March 2009 Accepted in revised form: 20 July 2009:

Published online:

14 August 2009

This article was presented as a scientific paper at the Asia ARVO Congress,

Hyderabad, India in January 2009.

\begin{abstract}
Purpose The current medical environment demands that quality health care is delivered at an affordable cost through the use of objective, unbiased clinical data. This study was undertaken to review the current literature on bevacizumab for age-related macular degeneration and its value in determining best clinical practice. Methods Randomised controlled trials (RCTs) and observational studies that met the Strengthening the Reporting of Observational Studies in Epidemiology (STROBE) criteria were identified from the current literature for further analysis. Data concerning treatment dosing regimens, response to treatment, complications, and factors influencing outcome and safety were extracted and compiled into a database.

Results As of January 2009, there were 5 RCTs that compared the outcomes of bevacizumab to other treatment options and 50 studies that met the STROBE criteria with similar visual and anatomical outcomes between RCTs and observational studies. Although the doses and dosing frequencies varied between the studies, the mean gain in vision at 3 months was $+7.76 \pm 5.4$ ETDRS letters (range +2 to +14.4 ); an effect that was maintained at 6 months in studies with longer follow-up. Predominantly classic lesions were the most responsive of all lesion subtypes. The complication profiles/rates were similar to those reported with other anti-vascular endothelial agents.

Conclusions There is sufficient scientific and statistical evidence to advocate the effective use of OCT-guided administration of
\end{abstract}

S Jyothi', H Chowdhury', M Elagouz ${ }^{1,2}$,

S Sivaprasad intravitreal bevacizumab for neovascular AMD. This is reflected in our study outcome measures that are comparable to findings published from recent well-conducted RCTs on intravitreal ranibizumab at the same time point. Eye (2010) 24, 816-824; doi:10.1038/eye.2009.219; published online 14 August 2009

Keywords: bevacizumab; age-related macular degeneration (ARMD); choroidal neovascularisation $(\mathrm{CNV})$; treatment regimen; anti-VEGF (Vascular Endothelial Growth Factor); avastin

Introduction

The concept of vascular endothelial growth factor (VEGF) inhibition and its influence on modulating the behaviour of choroidal neovascularisation (CNV) marked a turning point in the treatment of neovascular age-related macular degeneration (AMD). ${ }^{1,2}$ Since then, two drugs, pegaptanib sodium and ranibizumab, have successfully qualified all the necessary phases of drug development to obtain licensing approval by regulatory bodies and form the mainstay of treatment for neovascular AMD. Pegaptanib sodium (Macugen; Eyetech Pharmaceuticals, New York, NY, USA) is constructed as an aptamer to target VEGF-A 165 whereas ranibizumab (Lucentis; Novartis Pharmaceuticals Corporation, East Hanover, NJ, USA) is an antibody fragment able to target all VEGF-A isoforms when delivered intravitreally. The VISION study demonstrated that 6-weekly intravitreal pegatanib sodium stabilised vision in $70 \%$ of cases and improved vision in only $6 \%{ }^{3}$ Subsequently, ranibizumab was shown to stabilise vision in 
nearly $95 \%$ of patients with $30 \%$ experiencing improvements in visual acuity; marking the first effective intravitreal therapy with the potential to recover visual loss secondary to AMD. ${ }^{4-6}$

Although ranibizumab gained Food and Drugs Administration approval in June 2006; bevacizumab (Avastin; Genentech, South San Francisco, CA, USA), a recombinant humanised monoclonal antibody against all VEGF-A isoforms originally developed to treat metastatic carcinoma of the colon and rectum, ${ }^{7}$ also showed considerable promise in improving vision albeit as an 'off label' intervention. ${ }^{8-10}$ More specifically, a case series by Michels et al demonstrated the benefits of systemic administration of bevacizumab in the management of $\mathrm{CNV}$ by reducing retinal thickening and improving visual acuity; ${ }^{8}$ which in turn encouraged further studies reporting similar outcomes when administered intravitreally., 90

Furthermore under the current economic pressures and cost/benefit criteria practised in the medical environment, the provision of quality healthcare at an affordable cost through the use of objective, unbiased clinical data has become paramount. Therefore, given that bevacizumab has presented as a cheaper alternative to the more refined FDA-approved ranibizumab with presumed similar clinical outcomes, bevacizumab is now being widely administered for the treatment of neovascular AMD despite the absence of FDA and drug licensing approval for ocular use. However, in practice, various dosing/frequency regimens have been implemented either as monotherapy or in combination with other therapies making it difficult for practitioners to determine the best clinical practice based on current literature.

The aim of this study is to review the current state of the literature on the use of bevacizumab for neovascular AMD to tease out available information that will help retinal specialist to better understand the use of the drug in this condition, although awaiting randomised controlled trials comparing ranibizumab and bevacizumab. The Strengthening the Reporting of Observational Studies in Epidemiology (STROBE) statement ${ }^{11-13}$ published in 2007 is a checklist of 22 standards for non-RCT studies to assess the validity/applicability of the study (Table 1) akin to the Consolidated Standards for Reporting Trials (CONSORT) $)^{14}$ statement used in RCTs. A group has recently published the use of STROBE criteria for studies on bevacizumab for neovascular AMD until October 2007. ${ }^{15}$ In this study, we have extended these findings to include RCTs and STROBE-qualified studies until January 2009. ${ }^{16-71}$

\section{Materials and methods}

We conducted a systematic search of MEDLINE (2005 to January 2009) and the National Institutes of Health clinical trial databases (up to January 2009) for randomised controlled trials (RCTs) and observational case series with at least 3-month follow-up, both prospective and retrospective, which met the STROBE criteria. The search strategy used both keywords and $\mathrm{MeSH}$ terms for the following terms or combinations: $C N V$; choroidal neovascularisation; anti-VEGF; bevacizumab; avastin; pegaptanib; macugen; ranibizumab; lucentis; age-related macular degeneration; age-related maculopathy. All RCTs were included. As the range of STROBE quality grade in a similar study was between 46 and $94 \%$, this study included all studies that met at least $50 \%$ of the STROBE standards. Two reviewers assessed inclusion into this study and consensus was reached by discussion between reviewers.

The primary parameters of interest were mean change in visual acuity and central retinal thickness. The data included number of patients, treatment dose and regimen, $\mathrm{CNV}$ subtypes, response to treatment at specific time points, complications, and factors influencing outcome and safety. All the visual acuities were converted into equivalent ETDRS letter score for analysis. In the case of studies that sequentially reported the longer follow-up of the same series of patients, the latest study with the longest follow-up was included. Data were entered into a Microsoft Excel 2000 (Microsoft Corporation, Redmond, WA, USA) datasheet for tabulation and descriptive statistics. Data were pooled where appropriate to assess the outcome measures at specific time points and the mean number of treatments required at any particular time point.

\section{Results}

The electronic searches found a total of 349 publications that reported the clinical outcomes of bevacizumab in neovascular AMD. A total of 55 reports on clinical outcomes met the inclusion criteria. These included 5 RCTs that compared bevacizumab to other treatment options and 50 STROBE-qualified studies, of which 12 studies evaluated the combination of bevacizumab with another treatment modality. A summary of the five RCTs have been tabulated in Table 2. A meta-analysis could not be performed as a consequence of the heterogeneity in study design.

\section{STROBE-qualified studies}

There were 50 studies that met at least $50 \%$ of the STROBE criteria. ${ }^{15}$ The total number of subjects in the studies varied from 6 to 266 (mean, 53; median, 45). Twelve of these studies assessed the effect of combination therapy of intravitreal bevacizumab with another agent. The follow-up of these studies ranged from 3 to 12 months. Nine studies had less than 6-month 
Table 1 The STROBE checklist of items for evaluation of observational studies ${ }^{12}$

\begin{tabular}{|c|c|c|}
\hline & & Recommendation \\
\hline \multirow[t]{2}{*}{ Title and abstract } & 1a & Indicate the study's design with a commonly used term in the title or the abstract. \\
\hline & $1 b$ & $\begin{array}{l}\text { Provide in the abstract an informative and balanced summary of what was done and } \\
\text { what was found }\end{array}$ \\
\hline \multicolumn{3}{|l|}{ Introduction } \\
\hline Background/rationale & 2 & Explain the scientific background and rationale for the investigation being reported \\
\hline Objectives & 3 & State specific objectives, including any prespecified hypotheses \\
\hline \multicolumn{3}{|l|}{ Materials and methods } \\
\hline Study design & 4 & Present key elements of study design \\
\hline Setting & 5 & Describe the setting or participating location \\
\hline \multirow{4}{*}{ Participants } & $6 a$ & Statement about institutional review board approval and consent \\
\hline & $6 \mathrm{~b}$ & Give the inclusion and exclusion criteria \\
\hline & $6 c$ & Describe the sources and methods of selection of participants \\
\hline & $6 \mathrm{~d}$ & Describe methods of follow-up \\
\hline \multirow[t]{2}{*}{ Treatments } & $7 \mathrm{a}$ & Drug dose(s) defined \\
\hline & $7 \mathrm{~b}$ & Drug administration described \\
\hline Variables & 8 & $\begin{array}{l}\text { Clearly define all outcomes, exposures, predictors, potential confounders, and effect } \\
\text { modifiers }\end{array}$ \\
\hline \multicolumn{3}{|l|}{ Data sources/measurement } \\
\hline Visual acuity & $9 \mathrm{a}$ & Define method of visual acuity measurement \\
\hline OCT & $9 \mathrm{~b}$ & Describe technique for OCT data \\
\hline Angiography & $9 \mathrm{c}$ & Describe technique for fluorescein angiography data \\
\hline Bias & 10 & Describe any efforts to address potential sources of bias \\
\hline Study size & 11 & Explain how the study size was arrived at \\
\hline \multirow[t]{4}{*}{ Statistical methods } & $12 \mathrm{a}$ & Describe all statistical methods, including those used to control for confounding \\
\hline & $12 b$ & Describe any methods used to examine subgroups and interactions \\
\hline & $12 \mathrm{c}$ & Explain how missing data were addressed \\
\hline & $12 \mathrm{~d}$ & If applicable, explain how loss to follow-up was addressed \\
\hline \multicolumn{3}{|l|}{ Results } \\
\hline \multirow[t]{3}{*}{ Participants } & $13 a$ & $\begin{array}{l}\text { Report the numbers of individuals at each stage of the study, eg, numbers potentially } \\
\text { eligible, examined for eligibility, confirmed eligible, included in the study, completing } \\
\text { follow-up, and analysed }\end{array}$ \\
\hline & $13 b$ & Previous treatment for nvAMD reported \\
\hline & $13 c$ & Flow diagram included \\
\hline \multirow[t]{4}{*}{ Descriptive data } & $14 \mathrm{a}$ & Baseline vision and imaging data reported \\
\hline & $14 \mathrm{~b}$ & Lesion type or size discussed \\
\hline & $14 \mathrm{c}$ & Indicate the number of participants with missing data for each variable of interest \\
\hline & $14 \mathrm{~d}$ & Summarise follow-up time, eg, average and total amount \\
\hline Main results & 15 & $\begin{array}{l}\text { Give unadjusted estimates and, if applicable, confounder-adjusted estimates and their } \\
\text { precision (eg, 95\% confidence intervals). Make clear which confounders were adjusted } \\
\text { for and why they were included }\end{array}$ \\
\hline Adverse events & 16 & Adverse events reported \\
\hline Other analyses & 17 & $\begin{array}{l}\text { Report other analyses done, eg, analyses of subgroups and interactions and sensitivity } \\
\text { analyses }\end{array}$ \\
\hline \multicolumn{3}{|l|}{ Discussion } \\
\hline Key results & 18 & Summarise key results with reference to study objectives \\
\hline Limitations & 19 & $\begin{array}{l}\text { Discuss limitations of the study, taking into account sources of potential bias or } \\
\text { imprecision. Discuss both direction and magnitude of any potential bias }\end{array}$ \\
\hline Interpretation & 20 & $\begin{array}{l}\text { Give a cautious overall interpretation of results considering objectives, limitations, } \\
\text { multiplicity of analyses, results from similar studies, and other relevant evidence }\end{array}$ \\
\hline Generalisability & 21 & Discuss the generalisability (external validity) of the study results \\
\hline \multicolumn{3}{|l|}{ Other information } \\
\hline Funding & 22 & Give the source of funding and the role of the funders for this study \\
\hline
\end{tabular}

This table is modified from Fung et al. ${ }^{15}$ 
Table 2 Randomised controlled trials comparing intravitreal bevacizumab with other treatment modalities

\begin{tabular}{|c|c|c|c|c|c|c|c|}
\hline Author (year) & $\begin{array}{l}\text { Dose of } \\
\text { bevacizumab; } \\
\text { frequency }\end{array}$ & $\begin{array}{c}\text { Number of } \\
\text { patients in } \\
\text { bevacizumab } \\
\text { arm }\end{array}$ & $\begin{array}{l}\text { Comparative } \\
\text { treatment } \\
\text { modality }\end{array}$ & $\begin{array}{l}\text { Number of } \\
\text { patients in } \\
\text { comparator } \\
\quad \text { arm }\end{array}$ & $\begin{array}{l}\text { Length of } \\
\text { follow-up } \\
\text { (months) }\end{array}$ & $\begin{array}{l}\text { Visual change in } \\
\text { bevacizumab } \\
\text { group (ETDRS) }\end{array}$ & $\begin{array}{l}\text { Visual change in } \\
\text { comparative } \\
\text { group (ETDRS) }\end{array}$ \\
\hline Bashshur $(2007)^{26}$ & $2.5 \mathrm{mg} ; \mathrm{PRN}$ & 32 & PDT & 30 & 6 & 12 & -6 \\
\hline Hahn $(2007)^{44}$ & $1 \mathrm{mg} ; 3+\mathrm{PRN}$ & 10 & $\begin{array}{l}\text { SPDT + IVTA } \\
\text { RPDT + IVTA }\end{array}$ & $\begin{array}{l}10 \\
10\end{array}$ & 3 & 12 & $\begin{array}{c}-7 \\
-0.5\end{array}$ \\
\hline Lazic $(2007)^{51}$ & $1.25 \mathrm{mg}$; ST & 54 & $\begin{array}{l}\text { PDT + IVB } \\
\text { PDT }\end{array}$ & $\begin{array}{l}52 \\
50\end{array}$ & 3 & 1 & $\begin{array}{c}12.3 \\
0\end{array}$ \\
\hline Sacu $(2009)^{65}$ & $1 \mathrm{mg} ; 3+\mathrm{PRN}$ & 14 & PDT + IVTA & 14 & 12 & 8 & -3 \\
\hline Weigert $(2008)^{70}$ & $1 \mathrm{mg} ; 3+\mathrm{PRN}$ & 14 & PDT + IVTA & 14 & 6 & 11 & 0 \\
\hline
\end{tabular}

PRN, pro re nata; PDT, photodynamic therapy; SPDT, standard fluence PDT; RPDT, reduced fluence PDT; ETDRS, early treatment diabetic retinopathy study; IVTA, intravitreal triamcinolone; IVB, intravitreal bevacizumab; ST, single Treatment.

follow-up period whereas only three studies had completed 12-month follow-up. The doses of bevacizumab administered varied from $1 \mathrm{mg}$ to $2.5 \mathrm{mg}$, although most studies used $1.25 \mathrm{mg} / 0.05 \mathrm{ml}(n=36)$. Two most commonly used dosing regimen included a pro re nata (PRN) regime guided by optical coherent tomography (OCT) and visual acuity $(n=23)$ and a loading dose of 6-weekly bevacizumab followed by an OCT-guided PRN approach $(n=20)$. The percent of STROBE criteria met ranged from 50 to $88 \%$ (mean, $68 \%$; median, $68 \%)$. Most studies (88\%) used standardised reporting of outcomes similar to RCTs on these antiVEGF agents. Therefore, pooling of data from these studies was possible to provide a better estimate of the effect of intravitreal bevacizumab in neovascular AMD. Despite meeting STROBE criteria, some case series could not be pooled due to differing inclusion criteria. The major drawback was the lack of long-term follow-up to estimate long-term outcomes.

\section{Visual outcomes}

We compared the visual outcomes in the bevacizumab arms of all the RCTs (Figure 1), all of which reported similar results apart from that by Laziæ et al, with a mean gain of +6.91 ETDRS letters (range 1-12) at 3 months, +8.8 letters at 6 months ( 3 studies), and +8 letters at 12 months (1 study). The poorer outcome of bevacizumab reported by Laziæ et al at 3 months may be attributed to the single dose used in the study. The mean visual outcome improved by +6 letters ETDRS at 1 month but the effect was not sustained at 3 months. The pooled data from STROBE-selected studies showed a mean gain of $+7.57 \pm 4.86 \mathrm{SD}$ letters at an average follow-up of 6 months.

As the inclusion criteria of the five RCTs were not significantly different, the data on visual outcomes of all the bevacizumab arms (all doses inclusive) of the five

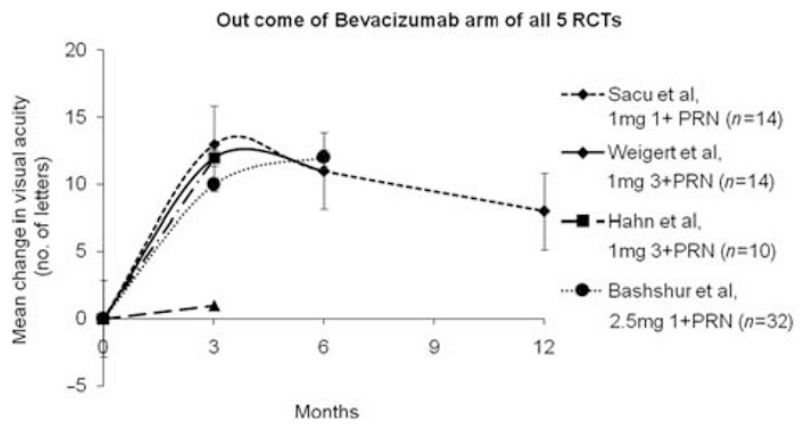

Figure 1 Mean change of visual acuity (VA) score (ETDRS letters) in the bevacizumab arms of all the five randomised controlled trials. Vertical bars represent \pm 1 standard error of the mean.

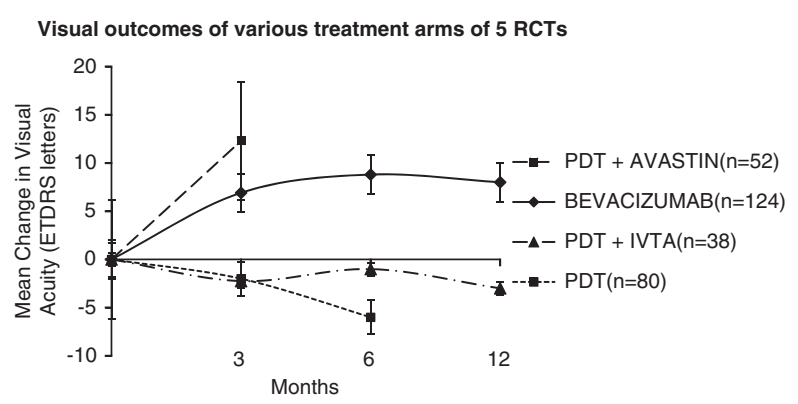

Figure 2 Mean change of visual acuity (VA) score (ETDRS letters) in various treatment arms at various time points in the five randomised controlled trials. Vertical bars represent \pm 1 standard error of the mean.

RCTs were pooled and then compared to the other treatment options at similar time frames (Figure 2). The other treatment options were a combination of photodynamic therapy (PDT) and bevacizumab, PDT and intravitreal triamcinolone and PDT monotherapy. Bevacizumab monotherapy and the combination of bevacizumab and PDT produced better outcomes than other treatment modalities, with combination therapy 


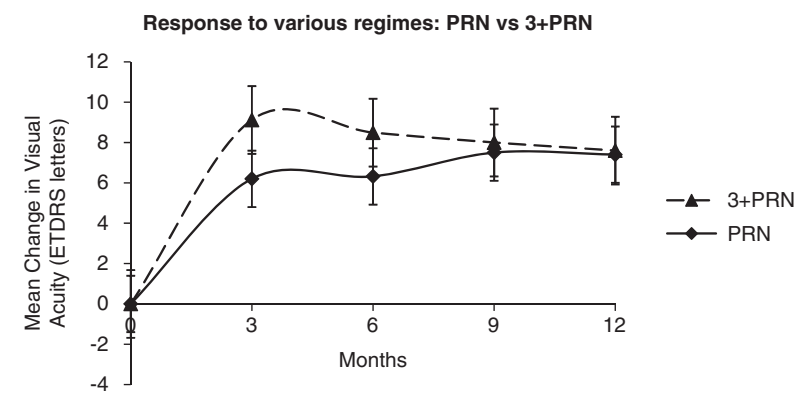

Figure 3 Mean change of visual acuity (VA) score (ETDRS letters) over time comparing various treatment doses. Vertical bars represent \pm 1 standard error of the mean.

demonstrating a better outcome in the short term (3 months).

\section{Effects of various doses of bevacizumab}

The various doses of bevacizumab reported in literature are $1 \mathrm{mg}{ }^{41,44,65,68,70} 1.25 \mathrm{mg}, 1.5 \mathrm{mg}^{23,32,33,49} 2 \mathrm{mg}^{33}$ $2.5 \mathrm{mg}^{22,26-28}$ ( $n=5$ for $1 \mathrm{mg} ; n=4$ for $1.5 \mathrm{mg} ; n=1$ for $2 \mathrm{mg}$ and $n=4$ for $2.5 \mathrm{mg}$ ). The pooled data of these doses indicated a dose-dependent response to the drug, whereas in higher doses they showed a better response (Figure 3). However, these data have to be further evaluated as most studies used $1.25 \mathrm{mg} / 0.05 \mathrm{ml}$ with very few studies using other doses.

\section{Effects of dosing frequency of bevacizumab on outcomes}

Two dosing frequencies were commonly practised in the literature. The first regimen included a loading dose of 6-weekly intravitreal bevacizumab for three doses followed by PRN doses as administered on the treating physician's discretion; whereas the second implemented a PRN schedule from the start of the therapy guided by OCT features of recurrent or persistent fluid and/or drop in vision. Figure 4 illustrates the visual outcomes of both these dosing frequencies. The initial gain in vision appears greater in patients given a loading dose; however, this effect was not sustainable at 12 months.

\section{The influence of baseline characteristics}

The outcome was better in treatment-naive lesions as compared to pretreated eyes. Pooled data indicated that patients with better baseline visual acuity fared better initially at 3 months but had no influence at 6 months. There was no correlation between the final best-achieved corrected visual acuity and the baseline central retinal thickness (data not shown). Reports that studied the response of the treatment in various angiographic subtypes of CNV were pooled to assess whether the



Figure 4 Mean change of visual acuity (VA) score (ETDRS letters) over time in the two treatment regimes. Vertical bars represent \pm 1 standard error of the mean.

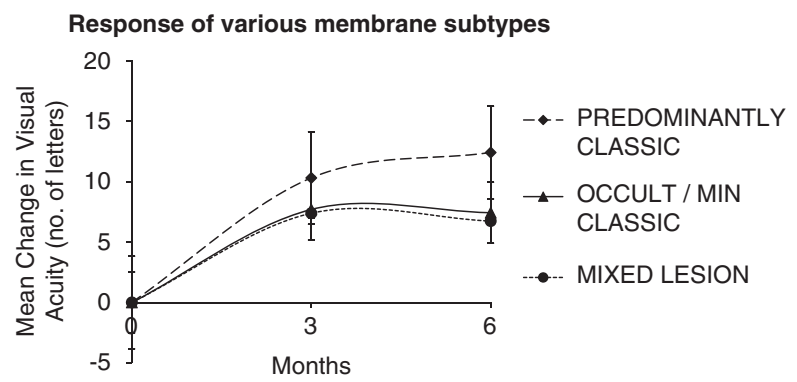

Figure 5 Mean change of visual acuity (VA) score (ETDRS letters) in various CNV subtypes. Vertical bars represent \pm 1 standard error of the mean.

effects of bevacizumab was dependent on the CNV subtype (Figure 5). Predominantly classic membranes were most responsive of all lesion subtypes.

\section{Mean number of treatments}

The mean number of treatments in the studies on intravitreal monotherapy was $2.94 \pm 0.8$ at 6 months. The different treatment protocols did not influence the number of treatments required.

\section{Combination treatments}

A total of 12 studies assessed the efficacy and safety of combining intravitreal bevacizumab with another treatment option. The most common combination tried was with PDT. ${ }^{17,18,22,23,32,35,49,50,54,61,66}$ Intravitreal bevacizumab was administered at the same session to up to 14 days post-PDT. The mean number of PDT sessions required at 6 months was 1.4 and the average intravitreal bevacizumab therapy was 2 (range 1-4) at 6 months. The mean gain in vision was +8.85 which is similar to that obtained in the RCT by Laziæ et al and superior to intravitreal bevacizumab monotherapy. ${ }^{51}$ One small 
series assessed the effects of triple therapy (intravitreal triamcinolone, PDT and bevacizumab) and +17 letters gain was noted at 6 months. ${ }^{17}$ A larger series by Augustin et $a l^{23}$ studied 104 eyes treated with PDT, intravitreal dexamethasone and bevacizumab, and oral minocycline, and obtained a mean improvement of +8 letters at 10 months with a low number of retreatments. Nonetheless, this procedure required vitrectomy with retrobulbar anaesthesia.

\section{Complications}

The cumulative incidence of ocular complications reported with intravitreal bevacizumab in neovascular AMD per 100 patients include endophthalmitis -0.2, retinal pigment epithelial tears -1.8 , sub retinal haemorrhage -0.21 , inflammation -0.48 , retinal detachment -0 , vitreous haemorrhage -0 , and lens injury -0.18 . The cumulative incidence of thromboembolic phenomenon was 0.2 and death in 0.06 .

\section{Discussion}

It may be argued that the gold standard for evidencebased medicine is a systematic review of RCTs. However, intravitreal bevacizumab is widely used in various ocular conditions in the absence of rigorous drug development phases or regulatory licensing protocols. Thus the basis of such clinical practice in this particular circumstance is not based on the highest quality of clinical evidence; however, a recent study that applied the STROBE standards on studies that reported clinical outcomes on bevacizumab for neovascular AMD demonstrated that although the average reporting score of these studies were lower than that of RCTs on the whole, some studies did indeed obtain higher STROBE scores. ${ }^{15}$ Hence, this demonstrates that there are useful studies with considerable evidence-based bearing that are available on this treatment effect outside RCTs and that the pooling of data from well-conducted RCTs and STROBEqualified studies alike are useful under these circumstances.

There are five RCTs that compared bevacizumab to other treatment modalities. Although the doses and dosing frequency varied between these studies, the mean gain in vision at 3 months was similar to that achieved with monthly intravitreal ranibizumab at the same time point in well-conducted RCTs. This effect was maintained at 6 months in studies with longer follow-up. However, there are no long-term data on the sustained effect of this drug.

Based on this study, the visual outcomes with bevacizumab does not differ significantly to the MARINA and ANCHOR studies on ranibizumab for neovascular AMD., ${ }^{4,5}$ The predominantly classic lesions did better with both drugs. The profile and rate of complications were also similar with both agents.

Furthermore a dose-response relationship was also noted with bevacizumab, whereby higher doses of $2.5 \mathrm{mg}$ showed a better treatment outcome compared to $1 \mathrm{mg}$ dosing. However, as most studies implemented a $1.25 \mathrm{mg} / 0.05 \mathrm{ml}$ regimen it is not clear if these may have biased our findings and it would be invaluable for us to further evaluate the optimal dose of bevacizumab in neovascular AMD.

There have been a number of schools of thought as to the optimal administration protocol for this drug in the management of CNV. This analysis supports the notion that a loading dose of three injections followed by an OCT-guided retreatment criterion provides better visual outcomes than the PRN schedule. These findings are in keeping with the rationale of the PrONTO study, which demonstrated that treatment benefits similar to monthly treatments of ranibizumab could be achieved by a loading dose of three injections and minimising the number of injections using a OCT-guided treatment algorithm. ${ }^{40,75}$ This regimen may also potentially reduce the ocular or systemic adverse effects of prolonged and constant VEGF inhibition.

A two-prong approach combining PDT and intravitreal bevacizumab is worth exploring, as the analysis indicates significant visual gain and reduced retreatment rates. Although, this can be explained by the synergistic effects of the different mechanisms of action of these treatment options, a similar effect has not been noted with wellconducted randomised trials involving ranibizumab and pegaptanib.

Despite higher doses used in some studies, bevacizumab was well tolerated and the safety profile was no different from other recent surveillance reports ${ }^{72-74}$ or indeed other published RCTs on ranibizumab. ${ }^{4,5}$ However, the actual incidence may be subject to publication bias.

\section{Conclusion}

Analyses of the available STROBE-qualified studies and RCTS have shown that the clinical outcomes and safety profile of intravitreal bevacizumab are similar to those from well-conducted trials of intravitreal ranibizumab in neovascular AMD in the short term. However, the optimal dose and the long-term outcomes need further evaluation. We await the 2-year outcomes of the ongoing randomised clinical trials comparing various treatment strategies of intravitreal bevacizumab to ranibizumab in neovascular AMD, the NEI funded CATT trial in the United States, and the HTA-funded IVAN trial in the United Kingdom.

\section{Conflict of interest}

The authors declare no conflict of interest. 
Summary

\section{What was known before}

- Bevacizumab is unlicenced for intraocular use.

- Several studies have used bevacizumab in neovascular age related macular degeneration

- The outcomes differ between studies.

What this study adds

- This study is a comprehensive review of studies that assessed the outcomes of bevacizumab in neovascular age related macular degeneration.

- Only studies that met the CONSORT and STROBE quality grades were reviewed allowing for a detailed assessment of several aspects of the outcomes of bevacizumab in neovascular age related macular degeneration.

- The study provides useful and unbiased clinical data on the drug while outcomes of the CATT and IVAN trials are awaited.

\section{References}

1 Adamis AP, Shima DT. The role of vascular endothelial growth factor in ocular health and disease. Retina 2005; 25(2): 111-118.

2 Ferrara N. Vascular endothelial growth factor: basic science and clinical progress. Endocr Rev 2004; 25(4): 581-611.

3 Gragoudas ES, Adamis AP, Cunningham Jr ET, Feinsod M, Guyer DR. VEGF inhibition study in ocular neovascularization clinical trial group. Pegaptanib for neovascular age-related macular degeneration. $N$ Engl J Med 2004; 351(27): 2805-2816.

4 Brown DM, Michels M, Kaiser PK, Heier JS, Sy JP, Ianchulev T, ANCHOR Study Group. Ranibizumab versus verteporfin photodynamic therapy for neovascular age-related macular degeneration: Two-year results of the ANCHOR study. Ophthalmology 2009; 116(1): 57-65.

5 Rosenfeld PJ, Brown DM, Heier JS, Boyer DS, Kaiser PK, Chung CY, MARINA Study Group. Ranibizumab for neovascular age-related macular degeneration. $N$ Engl J Med 2006; 355(14): 1419-1431.

6 Liew G, Mitchell P, Gillies MC, Wong TY, Rosenfeld PJ, Brown DM et al. Ranibizumab for neovascular age-related macular degeneration. $N$ Engl J Med 2007; 356: 747-750.

7 Hurwitz H, Fehrenbacher L, Novotny W, Cartwright T, Hainsworth J, Heim W et al. Bevacizumab plus irinotecan, fluorouracil, and leucovorin for metastatic colorectal cancer. $N$ Engl J Med 2004; 350(23): 2335-2342.

8 Michels S, Rosenfeld PJ, Puliafito CA, Marcus EN, Venkatraman AS. Systemic bevacizumab (avastin) therapy for neovascular age-related macular degeneration: twelveweek results of an uncontrolled open-label clinical study. Ophthalmology 2005; 112(6): 1035-1047.

9 Avery RL, Pieramici DJ, Rabena MD, Castellarin AA, Nasir MA, Giust MJ. Intravitreal bevacizumab (avastin) for neovascular age-related macular degeneration. Ophthalmology 2006; 113(3): 363-372.

10 Aggio BF, Eid Farah M, Melo GB. Intravitreal bevacizumab for occult choroidal neovascularization with pigment epithelium detachment in age-related macular degeneration. Acta Ophthalmol Scand 2006; 84(5): 713-714.

11 von Elm E, Altman DG, Egger M, Pocock SJ, Gøtzsche PC, Vandenbroucke JP. STROBE Initiative. The strengthening the reporting of observational studies in Epidemiology
(STROBE) statement: guidelines for reporting observational studies. Lancet 2007; 370: 1453-1457.

12 STROBE Statement. Strengthening the reporting of observational studies in epidemiology. STROBE checklist, version 4 (as published in Oct/Nov 2007). Available at:http://www.strobe-statement.org/Checklist.html. Accessed November 15, 2007.

13 Vandenbroucke JP, von Elm E, Altman DG, Gøtzsche PC, Mulrow CD, Pocock SJ et al. STROBE Initiative. Strengthening the reporting of observational studies in epidemiology (STROBE): explanation and elaboration. Epidemiology 2007; 18: 805-835.

14 Moher D, Schulz KF, Altman D, CONSORT Group (Consolidated Standards of Reporting Trials). The CONSORT statement: revised recommendations for improving the quality of reports of parallel-group randomized trials. JAMA 2001; 285: 1987-1991.

15 Fung AE, Palanki R, Bakri SJ, Depperschmidt E, Gibson A. Applying the CONSORT and STROBE statements to evaluate the reporting quality of neovascular age-related macular degeneration studies. Ophthalmology 2009; 116(2): 286-296 [epub 16 December 2008].

16 Aggio FB, Farah ME, Silva WC, Melo GB. Intravitreal bevacizumab for exudative age-related macular degeneration after multiple treatments. Graefes Arch Clin Exp Ophthalmol 2007; 245(2): 215-220.

17 Ahmadieh H, Taei R, Soheilian M, Riazi-Esfahani M, Karkhaneh R, Lashay A et al. Single-session photodynamic therapy combined with intravitreal bevacizumab and triamcinolone for neovascular age-related macular degeneration. BMC Ophthalmol 2007; 7: 10.

18 Ahmadieh H, Taei R, Soheilian M, Riazi-Esfahani M, Ahadi H. Single-session photodynamic therapy combined with intravitreal bevacizumab for neovascular age-related macular degeneration. Eur J Ophthalmol 2008; 18(2): 297-300.

19 Aisenbrey S, Ziemssen F, Völker M, Gelisken F, Szurman P, Jaissle $\mathrm{G}$ et al. Intravitreal bevacizumab (Avastin) for occult choroidal neovascularization in age-related macular degeneration. Graefes Arch Clin Exp Ophthalmol 2007; 245(7): 941-948 [epub 21 December 2006].

20 Algvere PV, Steén B, Seregard S, Kvanta A. A prospective study on intravitreal bevacizumab (Avastin) for neovascular age-related macular degeneration of different durations. Acta Ophthalmol 2008; 86(5): 482-489.

21 Arevalo JF, Fromow-Guerra J, Sanchez JG, Maia M, Berrocal MH, Wu L et al, Pan-American Collaborative Retina Study Group. Primary intravitreal bevacizumab for subfoveal choroidal neovascularization in age-related macular degeneration: results of the Pan-American Collaborative Retina Study Group at 12 months follow-up. Retina 2008; 28(10): 1387-1394.

22 Arias L, Caminal JM, Casas L, Masuet C, Badia MB, Rubio $\mathrm{M}$ et al. A study comparing two protocols of treatment with intravitreal bevacizumab (Avastin) for neovascular age-related macular degeneration. $\mathrm{Br} \mathrm{J}$ Ophthalmol 2008; 92(12): 1636-1641.

23 Augustin AJ, Puls S, Offermann I. Triple therapy for choroidal neovascularization due to age-related macular degeneration: verteporfin PDT, bevacizumab, and dexamethasone. Retina 2007; 27(2): 133-140.

24 Avery RL, Pieramici DJ, Rabena MD, Castellarin AA, Nasir MA, Giust MJ. Intravitreal bevacizumab (Avastin) for neovascular age-related macular degeneration. Ophthalmology 2006; 113(3): 363-372 e5. 
25 Azad RV, Khan MA, Chanana B, Azad S. Intravitreal bevacizumab for subfoveal choroidal neovascularization secondary to age-related macular degeneration in an Indian population. Jpn J Opthalmol 2008; 52(1): 52-56.

26 Bashshur ZF, Schakal A, Hamam RN, El Haibi CP, Jaafar RF, Noureddin BN. Intravitreal bevacizumab vs verteporfin photodynamic therapy for neovascularage-related macular degeneration. Arch Ophthalmol 2007; 125(10): 1357-1361.

27 Bashshur ZF, Bazarbachi A, Schakal A, Haddad ZA, El Haibi $C P$, Noureddin BN. Intravitreal bevacizumab for the management of choroidal neovascularization in age-related macular degeneration. Am J Ophthalmol 2006; 142(1): 1-9.

28 Bashshur ZF, Haddad ZA, Schakal A, Jaafar RF, Saab M, Noureddin BN. Intravitreal bevacizumab for treatment of neovascular age-related macular degeneration: a one-year prospective study. Am J Ophthalmol 2008; 145(2): 249-256.

29 Chen CY, Wong TY, Heriot WJ. Intravitreal bevacizumab (Avastin) for neovascular age-related macular degeneration: a short-term study. Am J Ophthalmol 2007; 143(3): 510-512.

30 Chen E, Kaiser RS, Vander JF. Intravitreal bevacizumab for refractory pigment epithelial detachment with occult choroidal neovascularization in age-related macular degeneration. Retina 2007; 27(4): 445-450.

31 Cleary CA, Cleary CA, Jungkim S, Ravikumar K, Kelliher C, Acheson RW et al. Intravitreal bevacizumab in the treatment of neovascular age-related macular degeneration, 6- and 9-month results. Eye 2008; 22(1): 82-86.

32 Costa RA, Jorge R, Calucci D, Melo Jr LA, Cardillo JA, Scott IU. Intravitreal bevacizumab (Avastin) in combination with verteporfin photodynamic therapy for choroidal neovascularization associated with age-related macular degeneration (IBeVe Study). Graefes Arch Clin Exp Ophthalmol 2007; 245(9): 1273-1280.

33 Costa RA, Jorge R, Calucci D, Cardillo JA, Melo Jr LA, Scott IU. Intravitreal bevacizumab for choroidal neovascularization caused by AMD (IBeNA Study): results of a phase 1 dose-escalation study. Invest Ophthalmol Vis Sci 2006; 47(10): 4569-4578.

34 De Clercq C, Snyers B, Guagnini AP, Kozyreff A. Treatment of age-related macular degeneration with intravitreous injections of bevacizumab (Avastin): short-term results. Bull Soc Belge Ophtalmol 2007; 306: 15-21.

35 Dhalla MS, Shah GK, Blinder KJ, Ryan Jr EH, Mittra RA, Tewari A. Combined photodynamic therapy with verteporfin and intravitreal bevacizumab for choroidal neovascularization in age-related macular degeneration. Retina 2006; 26(9): 988-993.

36 Ehrlich R, Weinberger D, Priel E, Axer-Siegel R. Outcome of bevacizumab (avastin) injection in patients with age-related macular degeneration and low visual acuity. Retina 2008; 28(9): 302-1307.

37 Emerson MV, Lauer AK, Flaxel CJ, Wilson DJ, Francis PJ, Stout JT et al. Intravitreal bevacizumab (Avastin) treatment of neovascular age-related macular degeneration. Retina 2007; 27(4): 439-444.

38 Falkenstein IA, Cheng L, Morrison VL, Kozak I, Tammewar AM, Freeman WR. Standardized visual acuity results associated with primary versus secondary bevacizumab (avastin) treatment for choroidalneovascularization in agerelated macular degeneration. Retina 2007; 27(6): 701-706.

39 Fong KC, Kirkpatrick N, Mohamed Q, Johnston RL. Intravitreal bevacizumab (Avastin) for neovascular agerelated macular degeneration using a variable frequency regimen in eyes with no previous treatment. Clin Experiment Ophthalmol 2008; 36(8): 748-755.

40 Furino C, Boscia F, Recchimurzo N, Besozzi G, Cardascia N, Sborgia $L$ et al. Intravitreal bevacizumab for treatment-naïve subfoveal occult choroidal neovascularization in age-related macular degeneration. Acta Ophthalmol 2009; 87(4): 404-407 [epub 8 September 2008].

41 Geitzenauer W, Michels S, Prager F, Kornek G, Vormittag L, Rosenfeld $\mathrm{P}$ et al. Early effects of systemic and intravitreal bevacizumab (avastin) therapy for neovascular age-related macular degeneration. Klin Monatsbl Augenheilkd 2006; 223(10): 822-827.

42 Giansanti F, Virgili G, Bini A, Rapizzi E, Giacomelli G, Donati MC et al. Intravitreal bevacizumab therapy for choroidal neovascularization secondary to age-related macular degeneration: 6-month results of an open-label uncontrolled clinical study. Eur J Ophthalmol 2007; 17(2): 230-237.

43 Goff MJ, Johnson RN, McDonald HR, Ai E, Jumper JM, $\mathrm{Fu}$ A. Intravitreal bevacizumab for previously treated choroidal neovascularization from age-related macular degeneration. Retina 2007; 27(4): 432-438.

44 Hahn R, Sacu S, Michels S, Varga A, Weigert G, Geitzenauer $\mathrm{W}$ et al. Intravitreal bevacizumab versus verteporfin and intravitreal triamcinolone acetonide in patients with neovascular age-related macula degeneration. Ophthalmologe 2007; 104(7): 588-593.

45 Hughes MS, Sang DN. Safety and efficacy of intravitreal bevacizumab followed by pegaptanib maintenance as a treatment regimen for age-related macular degeneration. Ophthalmic Surg Lasers Imaging 2006; 37(6): 446-454.

46 Jonas JB, Libondi T, Ihloff AK, Harder B, Kreissig I, Schlichtenbrede $\mathrm{F}$ et al. Visual acuity change after intravitreal bevacizumab for exudative age-related macular degeneration in relation to subfoveal membrane type. Acta Ophthalmol Scand 2007; 85(5): 563-565.

47 Jonas JB, Ihloff AK, Harder B, Kreissig I, Schlichtenbrede F, Libondi $\mathrm{T}$ et al. Intravitreal bevacizumab versus triamcinolone acetonide for exudative age-related macular degeneration. Ophthalmic Res 2009; 41(1): 21-27 [epub 13 October 2008].

48 Krebs I, Lie S, Stolba U, Zeiler F, Felke S, Binder S. Efficacy of intravitreal bevacizumab (Avastin) therapy for early and advanced neovascular age-related macular degeneration. Acta Ophthalmol 2008; epub ahead of print 17 October 2008.

49 Ladewig MS, Karl SE, Hamelmann V, Helb HM, Scholl HP, Holz FG et al. Combined intravitreal bevacizumab and photodynamictherapy for neovascular age-related macular degeneration. Graefes Arch Clin Exp Ophthalmol 2008; 246: $17-25$.

50 Ladas ID, Kotsolis AI, Papakostas TD, Rouvas AA, Karagiannis DA, Vergados I. Intravitreal bevacizumab combined with photodynamic therapy for the treatment of occult choroidal neovascularization associated with serous pigment epithelium detachment in age-related macular degeneration. Retina 2007; 27(7): 891-896.

51 Lazić R, Gabrić N. Verteporfin therapy and intravitreal bevacizumab combined and alone in choroidal neovascularization due to age-related macular degeneration. Ophthalmology 2007; 114(6): 1179-1185.

52 Lazić R, Gabrić N. Intravitreally administered bevacizumab (Avastin) in minimally classic and occult choroidal neovascularization secondary to age-related macular degeneration. Graefes Arch Clin Exp Ophthalmol 2007; 245(1): 68-73. 
53 Lazić R, Gabrić N, Dekaris I, Sarić B, Gavrić M. Intravitreal bevacizumab (Avastin) in treatment of neovascular age-related macular degeneration. Coll Antropol 2007; 31(Suppl 1): 77-81.

54 Lazić R, Gabrić N, Dekaris I, Gavrić M, Bosnar D. Photodynamic therapy combined with intravitreal bevacizumab (Avastin) in treatment of choroidal neovascularization secondary to age-related macular degeneration. Coll Antropol 2007; 31(Suppl 1): 71-75.

55 Levy J, Shneck M, Rosen S, Klemperer I, Rand D, Weinstein $\mathrm{O}$ et al. Intravitreal bevacizumab (avastin) for subfoveal neovascular age-related macular degeneration. Int Ophthalmol 2008; epub ahead of print 11 June 2008.

56 Lux A, Llacer H, Heussen FM, Joussen AM. Nonresponders to bevacizumab therapy of choroidal neovascular lesions. Br J Ophthalmol 2007; 91(10): 1318-1322.

57 Madhusudhana KC, Hannan SR, Williams CP, Goverdhan $\mathrm{SV}$, Rennie C, Lotery AJ et al Intravitreal bevacizumab (Avastin) for the treatment of choroidal neovascularization in age-related macular degeneration: results from 118 cases. Br J Ophthalmol 2007; 91(12): 1716-1717.

58 Mackiewicz J, Mankowska A, Dolar-Szczasny J, Zubilewicz A, Oleszczuk A, Nowomiejska K et al. Intravitreal bevacizumab (Avastin) injections for neovascular agerelated macular degeneration (AMD) - preliminary results. Klin Oczna 2007; 109(4-6): 146-149.

59 Melamud A, Stinnett S, Fekrat S. Treatment of neovascular age-related macular degeneration with intravitreal bevacizumab: efficacy of three consecutive monthly injections. Am J Ophthalmol 2008; 146(1): 91-95.

60 Mones JM, Lopez MA, Prieto JA, Rodriguez JP. Extrafoveal choroidal neovascularization secondary to wet age-related macular degeneration treated with intravitreal bevacizumab. Ophthalmic Surg Lasers Imaging 2007; 38(3): 226-228.

61 Navea A, Mataix J, Desco MC, Garcia-Pous M, Palacios E. One-year follow-up of combined customized therapy. Photodynamic therapy and bevacizumab for exudative age-related macular degeneration. Retina 2009; 29(1): 13-19.

62 Pedersen KB, Sjølie AK, Møller F. Intravitreal bevacizumab (Avastin) for neovascular age-related macular degeneration in treatment-naive patients. Acta Ophthalmol 2008; epub ahead of print 16 December 2008.

63 Pedersen R, Soliman W, Lund-Andersen H, Larsen M. Treatment of choroidal neovascularization using intravitreal bevacizumab. Acta Ophthalmol Scand 2007; 85(5): 526-533 [epub 18 May 2007].

64 Rich RM, Rosenfeld PJ, Puliafito CA, Dubovy SR, Davis JL, Flynn Jr HW et al. Short-term safety and efficacy of intravitreal bevacizumab (Avastin) for neovascular agerelated macular degeneration. Retina 2006; 26(5): 495-511.
65 Sacu S, Michels S, Prager F, Weigert G, Dunavoelgyi R, Geitzenauer W et al. Randomised clinical trial of intravitreal Avastin $v s$ photodynamic therapy and intravitreal triamcinolone: long-term results. Eye 2009; epub ahead of print 23 January 2009.

66 Smith BT, Dhalla MS, Shah GK, Blinder KJ, Ryan Jr EH, Mittra RA. Intravitreal injection of bevacizumab combined with verteporfin photodynamic therapy for choroidal neovascularization in age-related macular degeneration. Retina 2008; 28(5): 675-681.

67 Spaide RF, Laud K, Fine HF, Klancnik Jr JM, Meyerle CB, Yannuzzi LA. Intravitreal bevacizumab treatment of choroidal neovascularization secondary to age-related macular degeneration. Retina 2006; 26: 383-390.

68 Stifter E, Michels S, Prager F, Georgopoulos M, Polak K, Hirn C. Intravitreal bevacizumab therapy for neovascular age-related macular degeneration with large submacular hemorrhage. Am J Ophthalmol 2007; 144(6): 886-892.

69 Unver YB, Yavuz GA, Bekir N, Presti P, Li W, Sinclair SH. Relationships between clinical measures of visual function and anatomic changes associated with bevacizumab treatment for choroidal neovascularization in age-related macular degeneration. Eye 2009; 23(2): 453-460.

70 Weigert G, Michels S, Sacu S, Varga A, Prager F, Geitzenauer $\mathrm{W}$ et al. Intravitreal bevacizumab (Avastin) therapy versus photodynamic therapy plus intravitreal triamcinolone for neovascular age-related macular degeneration: 6-month results of a prospective, randomised, controlled clinical study. Br J Ophthalmol 2008; 92(3): 356-360.

71 Yoganathan P, Deramo VA, Lai JC, Tibrewala RK, Fastenberg DM. Visual improvement following intravitreal bevacizumab (Avastin) in exudative age-related macular degeneration. Retina 2006; 26(9): 994-998.

72 Schouten JS, La Heij EC, Webers CA, Lundqvist IJ, Hendrikse F. A systematic review on the effect of bevacizumab in exudative age-related macular degeneration. Graefes Arch Clin Exp Ophthalmol 2009; 247(1): $1-11$.

73 Fung AE, Rosenfeld PJ, Reichel E. The international intravitreal bevacizumab safety survey: using the internet to assess drug safety worldwide. Br J Ophthalmol 2006; 90(11): 1344-1349.

74 Wong LJ, Desai RU, Jain A, Feliciano D, Moshfeghi DM, Sanislo SR et al. Surveillance for potential adverse events associated with the use of intravitrealbevacizumab for retinal and choroidal vascular disease. Retina 2008; 28(8): 1151-1158.

75 Fung AE, Lalwani GA, Rosenfeld PJ, Dubovy SR, Michels S, Feuer WJ et al. An optical coherence tomography-guided, variable dosing regimen with intravitreal ranibizumab (Lucentis) for neovascular age-related macular degeneration. Am J Ophthalmol 2007; 143(4): 566-583. 